\title{
Malnutrition, Its Attributes, and Impact on Quality of Life: An Epidemiological Study among $\beta$-Thalassemia Major Children
}

\author{
Bijit Biswas $^{1, *}$, Narendra Nath Naskar², Keya Basu ${ }^{3}$, Aparajita Dasgupta ${ }^{4}$, Rivu Basu ${ }^{5}$, Bobby Paul ${ }^{4}$ \\ 'Department of Community and Family Medicine, All India Institute of Medical Sciences, Patna, India \\ ${ }^{2}$ Department of Public Health Administration, All India Institute of Hygiene and Public Health, Kolkata, India \\ ${ }^{3}$ Department of Pathology, Calcutta National Medical College and Hospital, Kolkata, India \\ ${ }^{4}$ Department of Preventive and Social Medicine, All India Institute of Hygiene and Public Health, Kolkata, India \\ ${ }^{5}$ Department of Community Medicine, R.G.Kar Medical College and Hospital, Kolkata, India
}

Background: India is home to a large number of thalassemic children. Despite malnutrition being an essential determinant of their therapeutic goals and quality of life (QoL), it was hardly ever explored. With this background, this study aimed to estimate the proportion of $\beta$-thalassemia major ( $\beta$-TM) children experiencing malnutrition, its attributes, and impact on their QoL.

Methods: This cross-sectional, hospital-based, analytical observational study was conducted among $328 \beta$-TM children attending the thalassemia day care unit of a medical college from May 2016 to April 2017, with a structured schedule. Data were analyzed following appropriate statistical methods using SPSS statistical package ver. 16.0 (SPSS Inc., Chicago, IL, USA).

Results: Among the study participants, $48.2 \%$ were malnourished with a mean body mass index of $13.9 \mathrm{~kg} / \mathrm{m}^{2}$. In the multivariable logistic regression model, participants' age (adjusted odds ratio [AOR], 1.15; 95\% confidence interval [CI], 1.02-1.29), caste (AOR, 2.11; 95\% CI, 1.23-3.60), mothers' educational level (AOR, 2.05; 95\% CI, 1.223.44), blood transfusion frequency (AOR, 1.25; 95\% CI, 1.16-1.31), and palpable spleen size (AOR, 1.22; 95\% CI, 1.08-1.37) were significant predictors of malnutrition after adjusting for pre-transfusion hemoglobin level and hemolytic facies status. In multiple linear regression analysis, malnutrition negatively impacted total QoL (unstandardized beta [standard error], -4.4 [1.7]; $\mathrm{P}=0.009$ ) and various domains of the study participants except the social and school domains adjusted for age, sex, caste, place of residence, parents' educational level, and socioeconomic status.

Conclusion: Almost half of the study participants had malnutrition. Malnutrition had a negative impact on their QoL.

Keywords: Malnutrition; Quality of Life; Thalassemia; Body Mass Index

Received: June 25, 2019, Revised: August 30, 2019, Accepted: September 5, 2019

${ }^{*}$ Corresponding Author: Bijit Biswas https://orcid.org/0000-0002-7609-6446

Tel: +91-8013071430, Fax: +91-03326313998,E-mail: drbijitbiswas@gmail.com 


\section{INTRODUCTION}

Thalassemia is an autosomal recessive single gene disorder affecting 200 million people globally with half of this patient group with new cases registered annually having the severe form of the disease (i.e., $\beta$-thalassemia major $[\beta-\mathrm{TM}])$. The disease is spreading to other countries that were not previously considered as endemic for thalassemia due to high population movement, thus becoming a global public health concern. ${ }^{1-3)}$ Southeast Asia is a known hotspot for thalassemia. ${ }^{2,4)}$ In India, nearly 12,000 infants born every year have the major form of the disease ( $10 \%$ of global burden) with half of these patients die before reaching adulthood. A large proportion of these early deaths are due to malnutrition. ${ }^{5-7)}$

Malnutrition in thalassemic children is multifactorial. Existing literature indicated that children with thalassemia have an average energy intake lower than the recommended daily dietary allowances as most of them belong to a more economically impoverished section of the society. As a result, they develop multiple micronutrient deficiencies (hidden hunger). Thus, socioeconomic status (a proxy indicator for food security) and literacy of parents play a major role in this regard. ${ }^{8,9)}$ On the contrary, suboptimal maintenance of therapeutic indices (i.e., blood hemoglobin $[\mathrm{Hb}]$ level, serum ferritin level, etc.) may lead to the development of iron overload-related complications (i.e., endocrinopathy, hepatitis, splenomegaly, and cardiac arrhythmia), which further complicates the growth process, while maintenance of optimal therapeutic indices promotes growth. ${ }^{10)}$

There are different ways of assessing malnutrition in children (e.g., weight for height, weight for age, and height for age), but body mass index (BMI) is the most frequently used and convenient method for estimating and assessing the level of malnutrition in children. Using BMI, children can be classified into different groups (i.e., obese, over- weight, underweight, and normal weight) according to their nutritional status, which helps in designing the interventions for different groups. In this case, we estimated the proportion of children who were either obese, overweight, or underweight in order to determine their malnutrition level. Thus, BMI for age was used to assess the malnutrition level among thalassemic children in the current study. ${ }^{11)}$

Extensive researches on various aspects of thalassemia have been conducted all over the world, but only a few studies explored the malnutrition level among thalassemic children, especially its impact on their quality of life (QoL). Few existing literatures suggest that malnutrition negatively impacted their QoL; however, to our knowledge, no previous study was conducted in the Indian subcontinent to confirm this issue. ${ }^{12)}$ With this background, the study aimed to estimate the proportion of $\beta$-TM children with malnutrition, its attributes, and impact on their QoL.

\section{METHODS}

The cross-sectional, hospital-based, analytical observational study was conducted in a thalassemia day care unit of Calcutta National Medical College and Hospital in West Bengal, situated in the eastern part of India, from May 2016 to April 2017. A total of $328 \beta$-TM children and their accompanying caregivers participated in the study. The following data were collected by the principal investigator himself following a structured schedule: sociodemographic (age, sex, place of residence, and parents' educational level), socioeconomic (per capita monthly family income), clinico-therapeutic (blood transfusion frequency, last pre-transfusion $\mathrm{Hb}$ level, spleen status, iron chelation status, and hemolytic facies), anthropometric (height and weight), and QoL (assessed using Peds4QL)-related data. Notably, the study was conducted only in children with known $\beta$-TM. These children were di-

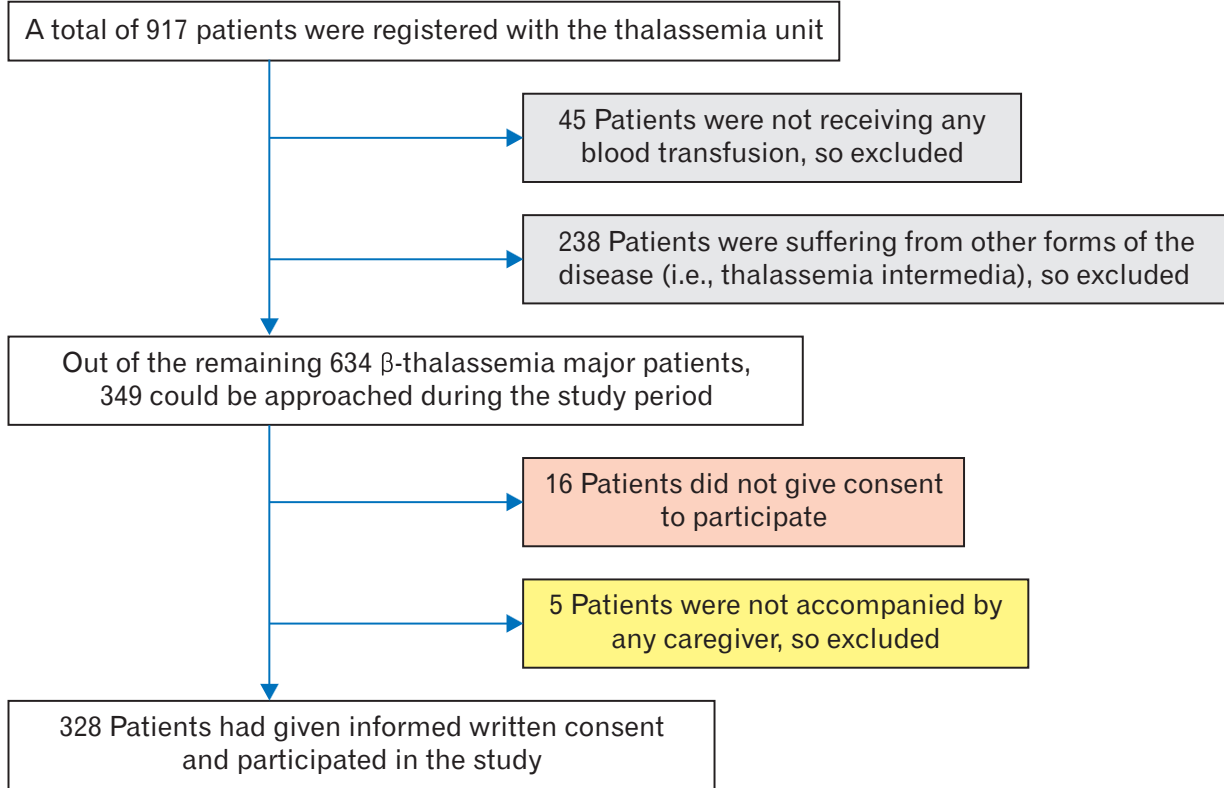

A total of 917 patients were registered with the thalassemia unit
Figure 1. Flow chart showing selection of study participants. 
agnosed with $\beta$-TM by the medical officer in charge of the thalassemia unit based on the following diagnostic criteria: a patient with $\mathrm{Hb}$ less than $7 \mathrm{gm} \%$ with $\mathrm{Hb} \mathrm{F} \geq 70 \%$ and $\mathrm{Hb} \mathrm{A}<30 \%$ on $\mathrm{Hb}$ electrophoresis at the time of diagnosis. After being diagnosed with $\beta$-TM, the children were attended at the thalassemia outpatient unit by a medical officer and were assessed to determine if the patients require blood transfusion (by $\mathrm{Hb}$ measurement and clinical examination) and other therapeutic interventions (iron chelators, vaccinations, etc.). Most of the visits involved follow-up care.

$\beta$-TM children who received at least 1 blood transfusion in the previous year, attended a thalassemia day care unit along with a caregiver during the study period, and consented to participate were included in the study. By contrast, those who were critically ill were excluded. Patients who are "critically ill" refer to thalassemic children who are bedridden and urgently require medical intervention in order to survive. One day in a week was allotted for data collection. On an average thalassemia unit, the outpatient department serves 15-20 $\beta$-TM patients every day. Every patient attended at the outpatient department was approached by the principal investigator and recruited for the study. Notably, the principal investigator of the study was a junior resident doctor then. The interview lasted for 15-20 minutes. On average, eight patients and their caregivers could be interviewed on a single day. Before each interview, the study participants were asked if they were interviewed before, to prevent duplication. A total of 41 days were allotted for data collection (excluding public holidays) in 1 year, and an average of 328 parents could be interviewed within the stipulated study period. Details are depicted in Figure 1.

During the study, the participants and their caregivers were acknowledged for participating in the study. Then, they were briefed by the researcher regarding the purpose and importance of the study. A written informed consent was obtained from all caregivers. Assent was also obtained from each child. Then, the caregivers of the study participants were interviewed to obtained the sociodemographic, socioeconomic, and QoL-related data followed by a review of patients' medical records to collect the clinico-therapeutic data, anthropometric measurements, and results of clinical examinations.

\section{Operational Definitions Used in the Study}

\section{1) Caregiver}

In the present study, any adult first-degree relative who accompanied the thalassemic child during his or her visit to the thalassemia unit of the hospital and currently living with and taking care of the patient was considered as a caregiver.

\section{2) Socioeconomic status}

It was assessed using the modified BG Prasad scale (2015). ${ }^{13)}$

\section{3) Splenomegaly}

It was determined by palpating the abdomen while the patient is lying supine.

\section{4) Weight}

Body weight was measured while the patient was wearing light clothes using a spring-loaded calibrated weighing scale. Participants were asked to step on the weighing scale with both feet at the center of the scale, face forward, remain still, place arms on both sides, and wait after removing any footwear. ${ }^{14)}$

\section{5) Height}

Height was measured while patient standing upright on a flat surface using a non-stretchable measuring tape fixed against the wall, taking the highest point of parietal tuberosity as the upper limit of the body. Patients were asked to stand with both the feet together, heels against the backboard, and knees straight after removing any footwear while measuring the height. ${ }^{14)}$

\section{6) Malnutrition}

The BMI of each patient was plotted on age- and sex-specific Centers

Table 1. Baseline characteristics of the study participants $(n=328)$

\begin{tabular}{|c|c|}
\hline Characteristic & Value \\
\hline Age (y) & $8.0 \pm 2.3$ \\
\hline \multicolumn{2}{|l|}{ Sex } \\
\hline Male & $177(54.0)$ \\
\hline Female & $151(46.0)$ \\
\hline \multicolumn{2}{|l|}{ Place of residence } \\
\hline Urban & $91(27.7)$ \\
\hline Rural & $237(72.3)$ \\
\hline \multicolumn{2}{|l|}{ Caste } \\
\hline General & $172(52.4)$ \\
\hline Other backward class & $45(13.7)$ \\
\hline Scheduled caste & $109(33.2)$ \\
\hline Scheduled tribe & $2(0.7)$ \\
\hline Per capita monthly family income in rupees & $1,643.4 \pm 883.0$ \\
\hline \multicolumn{2}{|l|}{ Socioeconomic status* } \\
\hline Class II (3,139-6,276) & $21(6.4)$ \\
\hline Class III $(1,883-3,138)$ & $79(24.1)$ \\
\hline Class IV (942-1,882) & $160(48.8)$ \\
\hline Class V $(<942)$ & $68(20.7)$ \\
\hline No. of blood transfusion received last year & $11.6 \pm 4.9$ \\
\hline Last pre-transfusion hemoglobin level (gm/dL) & $5.51 \pm 0.82$ \\
\hline \multicolumn{2}{|l|}{ Undergone splenectomy } \\
\hline Yes & $83(25.3)$ \\
\hline No & $245(74.7)$ \\
\hline Palpable spleen size (cm) & $3.94 \pm 2.64$ \\
\hline \multicolumn{2}{|l|}{ Iron chelators were taken } \\
\hline Yes & $306(93.3)$ \\
\hline No & $22(6.7)$ \\
\hline Duration since receiving iron chelators (mo) & $35.6 \pm 20.2$ \\
\hline \multicolumn{2}{|l|}{ Thalassemia facies } \\
\hline Present & $182(55.5)$ \\
\hline Absent & $146(44.5)$ \\
\hline Height (cm) & $113.7 \pm 11.3$ \\
\hline Weight $(\mathrm{kg})$ & $18.3 \pm 4.7$ \\
\hline Body mass index $\left(\mathrm{kg} / \mathrm{m}^{2}\right)$ & $13.9 \pm 1.6$ \\
\hline
\end{tabular}

Values are presented as mean \pm standard deviation or number (\%). *According to the modified BG Prasad scale (2015). 
for Disease Control and Prevention BMI charts, ${ }^{15)}$ and their nutritional status was categorized as follows: less than 5 th percentile, underweight; 5th to 84th percentile, healthy weight; 85th to 94th percentile, overweight; and $\geq 95$ th percentile, obese. Then, the proportions of malnutrition (underweight, overweight, and obese) participants were calculated to determine their malnutrition level.

\section{7) QoL score}

The items in the Peds4QL scale were reversed scored and linearly transformed to a $0-100$ scale: $0=100,1=75,2=50,3=25$, and $4=0$. The scores were obtained by adding the total items and the number of items answered. This way, the scores of each domain (physical, emotional, social, and school) and the total score were obtained. Higher scores indicate a more favorable QoL. ${ }^{16)}$

\section{Ethical Issues}

Ethical clearance from the respective institutional ethics committees (approval no., CNMC/7) of All India Institute of Hygiene and Public Health and Calcutta National Medical College and Hospital, Kolkata was taken before conducting the study. A written informed consent was obtained from the accompanying caregiver and child assent was taken from the participant before participating in the study. During data collection, their confidentiality was assured. The study was conducted as per the Helsinki Declaration of 1975, as revised in 2000 (available at http://www.wma.net/e/policy/17-c_e.html).

\section{Statistical Analysis}

Data were analyzed using SPSS ver. 16.0 (SPSS Inc., Chicago, IL, USA). First, a univariate logistic regression analysis was performed to ascertain the relationship between malnutrition among the study participants and its various attributes. Only those variables that were found

Table 2. Univariate and multivariable logistic regression analyses showing the predictors of malnutrition among thalassemic children $(n=328)$

\begin{tabular}{|c|c|c|c|}
\hline Variable & No. of malnutrition: yes (\%) & $\mathrm{OR}(95 \% \mathrm{Cl})$ & Adjusted OR (95\% Cl) \\
\hline Total & $158(48.2)$ & & \\
\hline Age (y, increasing) & - & $1.14(1.04-1.26)$ & $1.15(1.02-1.29)$ \\
\hline \multicolumn{4}{|l|}{ Sex } \\
\hline Female & $74(49.0)$ & $1.06(0.68-1.64)$ & - \\
\hline Male & $84(47.5)$ & Ref & \\
\hline \multicolumn{4}{|l|}{ Place of residence } \\
\hline Rural & $121(51.1)$ & $1.52(0.93-2.48)$ & - \\
\hline Urban & $37(40.7)$ & Ref & \\
\hline \multicolumn{4}{|l|}{ Caste } \\
\hline Scheduled caste/scheduled tribe & $62(55.9)$ & $1.59(1.01-2.53)$ & $2.11(1.23-3.60)$ \\
\hline General/other backward class & $96(44.2)$ & Ref & Ref \\
\hline \multicolumn{4}{|l|}{ Mothers educational level } \\
\hline Below primary & $73(54.9)$ & $1.57(1.10-2.45)$ & $2.05(1.22-3.44)$ \\
\hline Primary and above & $85(43.6)$ & Ref & Ref \\
\hline \multicolumn{4}{|l|}{ Fathers educational level } \\
\hline Below primary & 71 (52.2) & $1.32(0.85-2.04)$ & - \\
\hline Primary and above & $87(45.3)$ & Ref & \\
\hline \multicolumn{4}{|l|}{ Socioeconomic status } \\
\hline Class IV and V & $117(51.3)$ & $1.52(0.94-2.44)$ & - \\
\hline Class II and III & $41(41.0)$ & Ref & \\
\hline Blood transfusion frequency in the previous year (increasing) & - & $1.18(1.13-1.22)$ & $1.25(1.16-1.31)$ \\
\hline Last pre-transfusion hemoglobin level (gm/dL, decreasing) & - & $1.43(1.09-1.88)$ & $1.17(0.81-1.42)$ \\
\hline \multicolumn{4}{|l|}{ Receiving iron chelators } \\
\hline No & $13(59.1)$ & $1.60(0.66-3.86)$ & - \\
\hline Yes & $145(47.3)$ & Ref & \\
\hline Duration since receiving iron chelators (increasing) & - & $1.00(0.99-1.01)$ & - \\
\hline \multicolumn{4}{|l|}{ Splenectomy } \\
\hline No & $124(50.6)$ & $1.47(0.89-2.44)$ & - \\
\hline Yes & $34(41.0)$ & Ref & \\
\hline Palpable spleen size (cm, increasing) & - & $1.09(1.02-1.16)$ & $1.22(1.08-1.37)$ \\
\hline \multicolumn{4}{|l|}{ Thalassemia facies } \\
\hline Present & $101(55.5)$ & $1.94(1.25-3.03)$ & $1.24(0.73-2.11)$ \\
\hline Absent & $57(39.0)$ & Ref & Ref \\
\hline
\end{tabular}

In the multivariable logistic regression model, participants' age, caste, mothers' educational level, frequency of blood transfusion in the previous year, last pre-transfusion hemoglobin level in $\mathrm{gm} / \mathrm{dL}$, and palpable spleen size in $\mathrm{cm}$ were significant variables. Moreover, thalassemia facies status was determined. Bold type is considered statistically significant.

$\mathrm{OR}$, odds ratio; $\mathrm{Cl}$, confidence interval; Ref, reference. 
to be significant in the univariate analysis were entered into the multivariable logistic regression model by forced entry method. The strength of associations was assessed using odds ratio and its $95 \%$ confidence interval (CI). To determine the impact of malnutrition on QoL and its various domains, a multiple linear regression analysis was conducted adjusting for age, sex, caste, place of residence, parents' educational level, and socioeconomic status. In this case, the strength of association was assessed by unstandardized beta and standard error (SE). Statistical significance for all analyses was set at $\mathrm{P}<0.05$.

\section{RESULTS}

Among the study participants, $48.2 \%$ were malnourished with a mean BMI of $13.9 \pm 1.6 \mathrm{~kg} / \mathrm{m}^{2}$. Notably, all malnourished children in the current study were underweight. None of the children were overweight or obese. Most of the study participants (37.2\%) were aged between 11 and 12 years (range, 5-12 years). There was almost equal representation of both sexes. Most of the study participants were diagnosed with thalassemia within the first year of their lives (56.5\%) with a mean age at diagnosis of 20.25 months. Three-fifth (61.3\%) of them had a palpable spleen with a palpable spleen size of 1-8 $\mathrm{cm}$. Majority of the study participants (63.7\%) received blood transfusion once or less than once a month, and most of the patients had a pre-transfusion $\mathrm{Hb}$ level of 5.3-5.9 gm/dL (35.4\%). One-fifth (20.6\%) of participants were taking iron chelators in the last 13-24 months (mean \pm standard deviation, 35.6 \pm 20.2 months) (Table 1).

In the multivariable logistic regression model, the participants with higher age (adjusted odds ratio [AOR], 1.15; 95\% CI, 1.02-1.29), who belonged to a scheduled caste (SC)/scheduled tribe (ST) (AOR, 2.11; 95\% CI, 1.23-3.60), had mothers who only finished primary school or below (AOR, 2.05; 95\% CI, 1.22-3.44), who had frequent blood transfusions (AOR, 1.25; 95\% CI, 1.16-1.31), and with a palpable spleen size (AOR, 1.22; 95\% CI, 1.08-1.37) were at higher risk of malnutrition after adjusting for pre-transfusion $\mathrm{Hb}$ level and hemolytic facies status. The independent variable in the model was the $30.3 \%$ variability of the malnutrition level among the study participants with a predictive accuracy rate of $72.6 \%$, while a Hosmer-Lemeshow P-value of 0.310 indicated acceptable goodness of fit (Table 2).

In the multiple linear regression analysis, malnutrition negatively impacted total QoL (B [SE], -4.4 [1.7]; $\mathrm{P}=0.009$ ) and its various do- mains, except for social and school domain, after adjusting with for age, sex, caste, place of residence, parents' educational level, and socioeconomic status (Table 3).

\section{DISCUSSION}

This facility-based cross-sectional study was aimed to determine the proportion of $\beta$-TM children with malnutrition, its attributes, and impact on their QoL. In the present study, half (48.2\%) of the study participants were malnourished, which was higher than the value reported in a study of Trehan et al. ${ }^{17)}$ (26.7\%) and a study of Pemde et al. ${ }^{18)}$ (24.2\%), lesser than the value reported in a study of Kumari et al. ${ }^{19}$ ) (91.8\%) and a study of Sheikh et al. ${ }^{20)}(64.3 \%)$, and similar to the value reported in a study of Mirhosseini et al. ${ }^{21)}$ (44.3\%) and a study of Fahim et al. ${ }^{22)}(43.0 \%)$. The variability of the findings may be attributed to the differences in the participants' age, ethnicity, and geographical plausibility.

In the present study, a significant association between study participants age and malnutrition status was observed, which was similar to the findings of a study of Sheikh et al. ${ }^{20)}$ and a study of Mirhosseini et al. ${ }^{21)}$ Those who belonged to the SC/ST were more likely to have malnutrition. This may be due to the following reasons: in India, those who belong to a SC/ST are more economically deprived than those in other castes. ${ }^{13)}$ Similarly, mothers' educational level also significantly impacted malnutrition level of the study participants, which was inconsistent with the findings of a study of Sheikh et al., ${ }^{20)}$ which did not find any association between parents' educational status and growth of their children. The variability of results may be due to the small sample size used in a study of Sheikh et al. ${ }^{20)}$ As most of the study participants belonged to a more economically impoverished section of the society, such as those living in remote rural areas, the high incidence of malnutrition may not only be due to their illness but also to their inability to afford healthy and nutritious meals. Although their household-level food security was not measured, their caste, socioeconomic status, and educational level may be considered as a proxy indicator.

The implicated therapeutic causes of malnutrition in thalassemia are prolonged use of iron chelators, multiple endocrinopathies, and hypoxia at the cellular level due to anemia, while higher number of blood transfusion further complicates the normal growth process,

Table 3. Impact of malnutrition on QoL of the study participants $(n=328)$

\begin{tabular}{|c|c|c|c|c|c|c|}
\hline Variable & №. $(\%)$ & Physical domain & Emotional domain & Social domain & School domain & Total QoL score \\
\hline \multicolumn{7}{|l|}{ Malnutrition } \\
\hline Yes & $158(48.2)$ & $-6.3(2.2)^{\star}$ & $-4.3(1.6)^{\star}$ & $-1.4(2.7)^{\star}$ & $-4.7(3.3)^{\star}$ & $-4.4(1.7)^{\star}$ \\
\hline No & $170(51.8)$ & Ref & Ref & Ref & Ref & Ref \\
\hline P-value ${ }^{\dagger}$ & - & 0.004 & 0.008 & 0.595 & 0.184 & 0.009 \\
\hline
\end{tabular}

Bold type is considered statistically significant.

QoL, quality of life; Ref, reference.

*Unstandardized beta (standard error) adjusted for age, sex, caste, place of residence, parents' educational level, and socioeconomic status. ‘By multiple linear regression analysis. 
even in children who are regularly receiving a blood transfusion. ${ }^{23-26)}$ In the present study, participants' age and frequency of blood transfusion were significant predictors of malnutrition. Similarly, those who had higher pre-transfusion $\mathrm{Hb}$ level had significantly lower chances of being malnourished, which was similar to the reports of Saxena. ${ }^{27)}$ It was a significant finding as maintenance of optimal $\mathrm{Hb}$ level promotes growth and prevents anemia-related complications as demonstrated by Taher et al. ${ }^{28)}$ Meanwhile, the mean pre-transfusion $\mathrm{Hb}$ level of our study participants was lower than that reported in previous studies conducted in India. ${ }^{18,19)}$ This may due to the higher proportions of undernourished patients in our study. Those who had larger spleen size and thalassemia facies were more likely to be malnourished. It may be because splenomegaly and thalassemia facies both indicate the severity of the disease. Similar observations were reported by Tantawy et al., ${ }^{29)}$ who reported that the "main indications for splenectomy are growth retardation and poor health," which supports our findings.

In the present study, malnutrition negatively impacted total QoL and its various domains. This finding was supported by the results of a study of Elalfy et al., ${ }^{12)}$ which reported higher weight percentile $(\geq 50)$ as a predictor of better QoL scores. This may be because a well-nourished child is more likely to cope up with the burden of a chronic disease like thalassemia resulting in higher QoL scores.

This study has some strengths; it was among the fewer studies that explored the proportion of $\beta$-TM children with malnutrition, its attributes, and impact on their QoL. In addition, the sample size used in this study is larger than that used in previous studies. Additionally, it used an adjusted regression analysis to determine the strength of association, which makes the evidence more conclusive and will further help in prioritizing interventions.

This study has some limitations. This was a cross-sectional study, which cannot establish the causal association between malnutrition and its various attributes; there may be other specific attributes (i.e., dietary factors) of malnutrition in thalassemic children that were not assessed in the study. On the contrary, chronic severe $\beta$-TM may itself could lead to anorexia, muscle wasting (e.g., cachexia), and undernutrition. There may be other factors affecting the QoL the thalassemic children, but the current study was designed to explore the impact of nutritional status on QoL of thalassemic children; hence, the other attributes of QoL were not assessed.

In conclusion, almost half of the participants had malnutrition. Malnutrition had a negative impact on their QoL. Therapeutic indices (pre-transfusion $\mathrm{Hb}$ level, spleen status, etc.) of the study participants were lower than those reported in previous studies and were considered as significant predictors of malnutrition. These findings expose the real, bitter picture of thalassemia management in our country, which is quite bothering. Maintenance of optimal therapeutic indices (i.e., pre-transfusion $\mathrm{Hb}$ level) of these children is warranted to prevent malnutrition and improve QoL.

\section{CONFLICT OF INTEREST}

No potential conflict of interest relevant to this article was reported.

\section{ACKNOWLEDGMENTS}

Authors want to express their gratitude towards all the thalassemic children and their caregivers for being part of the study. The data sets used and/or analysed during the current study are available from the corresponding author on reasonable request.

\section{ORCID}

Bijit Biswas: https://orcid.org/0000-0002-7609-6446

Narendra Nath Naskar: https://orcid.org/0000-0002-0654-9593

Keya Basu: https://orcid.org/0000-0002-4904-3840

Aparajita Dasgupta: https://orcid.org/0000-0002-8942-4162

Rivu Basu: https://orcid.org/0000-0003-4993-494X

Bobby Paul: https://orcid.org/0000-0003-0217-2458

\section{REFERENCES}

1. Kasper D, Fauci A, Hauser S, Longo D, Jameson JL, Loscalzo J. Harrison's principles of internal medicine. 19th ed. New York (NY): McGraw-Hill Medical Publishing; 2015.

2. Colah R, Gorakshakar A, Nadkarni A. Global burden, distribution and prevention of $\beta$-thalassemias and hemoglobin E disorders. Expert Rev Hematol 2010;3:103-17.

3. Sharma N, Gupta A, Gupta G. Assessment of serum ferritin, vitamin b12 and folic acid level in thalassemia. J Med Sci Clin Res 2017;5: 29910-4.

4. Weatherall DJ, Clegg JB. Inherited haemoglobin disorders: an increasing global health problem. Bull World Health Organ 2001;79:704-12.

5. World Health Organization. Management of haemoglobin disorders: report of a joint WHO-TIF meeting, Nicosia, Cyprus, 16-18 November 2007 [Internet]. Geneva: World Health Organization; 2008 [cited 2017 Dec 20]. Available from: http://apps.who.int/iris/bitstream/10665/ 43969/1/9789241597128_eng.pdf.

6. Ansari SH, Shamsi TS, Ashraf M, Farzana T, Bohray M, Perveen K, et al. Molecular epidemiology of $\beta$-thalassemia in Pakistan: far reaching implications. Indian J Hum Genet 2012;18:193-7.

7. Mohanty D, Colah RB, Gorakshakar AC, Patel RZ, Master DC, Mahanta J, et al. Prevalence of $\beta$-thalassemia and other haemoglobinopathies in six cities in India: a multicentre study. J Community Genet 2013;4: 33-42.

8. Skordis N, Kyriakou A. The multifactorial origin of growth failure in thalassaemia. Pediatr Endocrinol Rev 2011;8 Suppl 2:271-7.

9. Toulson Davisson Correia MI. Addressing the hidden burden of malnutrition for hospitalized patients. J Acad Nutr Diet 2018;118:37-9.

10. Telfer PT, Prestcott E, Holden S, Walker M, Hoffbrand AV, Wonke B. Hepatic iron concentration combined with long-term monitoring of serum ferritin to predict complications of iron overload in thalassaemia major. Br J Haematol 2000;110:971-7. 
11. Dinsdale H, Ridler C, Ells LJ. A simple guide to classifying body mass index in children [Internet]. Oxford: National Obesity Observatory; 2011 [cited 2017 Dec 20]. Available from: http://www.noo.org.uk/publications.

12. Elalfy MS, Farid MN, Labib JH, RezkAllah HK. Quality of life of Egyptian b-thalassemia major children and adolescents. Egypt J Haematol 2014;39:222-6.

13. Mangal A, Kumar V, Panesar S, Talwar R, Raut D, Singh S. Updated BG Prasad socioeconomic classification, 2014: a commentary. Indian J Public Health 2015;59:42-4.

14. World Health Organization. Global strategy on diet physical activity and health [Internet]. Geneva: World Health Organization; 2004 [cited 2017 Dec 20]. Available from: http://www.who.int/dietphysicalactivity/strategy/eb11344/strategy_english_web.pdf.

15. Centers for Disease Control and Prevention. National Center for Health Statistics: clinical growth charts [Internet]. Atlanta (GA): Centers for Disease Control and Prevention [cited 2017 Dec 20]. Available from: http://www.cdc.gov/growthcharts/clinical_charts.htm.

16. Varni JW. Scaling and Scoring of the Pediatric Quality of Life Inventory [Internet]. Lyon: Mapi Research Trust; 2017 [cited 2017 Dec 20]. Available from: http://www.pedsql.org/PedsQL-Scoring.pdf.

17. Trehan A, Sharma N, Das R, Bansal D, Marwaha RK. Clinicoinvestigational and demographic profile of children with thalassemia major. Indian J Hematol Blood Transfus 2015;31:121-6.

18. Pemde HK, Chandra J, Gupta D, Singh V, Sharma R, Dutta AK. Physical growth in children with transfusion-dependent thalassemia. Pediatr Health Med Ther 2011;2:13-9.

19. Kumari V, Upadhyay SK, Gupta V, Piplani KS, Bhatia BD. Growth retardation and malnutrition in children with thalassemia major. Indian J Prev Soc Med 2012;43:149-52.
20. Sheikh MA, Shakir MU, Shah M. The assessment of nutritional status of children with beta thalassemia major with body mass index. Pak J Med Health Sci 2017;11:262-5.

21. Mirhosseini NZ, Shahar S, Ghayour-Mobarhan M, Kamaruddin NA, Banihashem A, Yusoff NA, et al. Factors affecting nutritional status among pediatric patients with transfusion-dependent beta thalassemia. Mediterr J Nutr Metab 2013;6:45-51.

22. Fahim FM, Saad K, Askar EA, Eldin EN, Thabet AF. Growth parameters and vitamin D status in children with thalassemia major in upper Egypt. Int J Hematol Oncol Stem Cell Res 2013;7:10-4.

23. Brook CG, Thompson EN, Marshall WC, Whitehouse RH. Growth in children with thalassaemia major and effect of two different transfusion regimens. Arch Dis Child 1969;44:612-6.

24. Pantelakis S. Growth patterns in patients with thalassaemia major. Acta Paediatr Suppl 1994;406:109-10.

25. Fung EB. The importance of nutrition for health in patients with transfusion-dependent thalassemia. Ann N Y Acad Sci 2016;1368:40-8.

26. Fuchs GJ, Tienboon P, Linpisarn S, Nimsakul S, Leelapat P, Tovanabutra S, et al. Nutritional factors and thalassaemia major. Arch Dis Child 1996;74:224-7.

27. Saxena A. Growth retardation in thalassemia major patients. Int J Hum Genet 2003;3:237-46.

28. Taher AT, Musallam KM, Cappellini MD, Weatherall DJ. Optimal management of $\beta$ thalassaemia intermedia. Br J Haematol 2011;152:51223.

29. Tantawy AA, Adly AA, Ismail EA, Youssef OI, Ali ME. Growth differentiation factor-15 in children and adolescents with thalassemia intermedia: relation to subclinical atherosclerosis and pulmonary vasculopathy. Blood Cells Mol Dis 2015;55:144-50. 